\title{
Crescimento e atributos fenológicos dos cultivares de goiabeira-serrana em São Joaquim, SC
}

\author{
Marlise Nara Ciotta ${ }^{1}$, Karine Louise dos Santos ${ }^{2}$ e Mateus da Silveira Pasa ${ }^{3}$
}

\begin{abstract}
Resumo - A goiabeira-serrana é uma espécie de ocorrência espontânea na Região Sul do Brasil, Uruguai e Argentina pertencente à família Myrtaceae. Apesar de sua adaptação e potencial produtivo, ainda é pouco cultivada comercialmente, diferente do que ocorre em outros países onde a espécie foi introduzida e já vem sendo amplamente cultivada. Com vistas a propiciar o cultivo no Brasil, quatro cultivares comerciais foram lançados pela Epagri em parceria com a Universidade Federal de Santa Catarina. O objetivo deste estudo foi avaliar o desenvolvimento vegetativo, fenológico e produtivo dos cultivares ao longo de três safras. Observou-se que não existe diferença de desenvolvimento vegetativo entre eles, em termos de diâmetro de tronco e altura de planta. Quanto ao grau de produção, pelo menos em duas safras avaliadas, os cultivares Alcântara e Helena foram superiores aos demais e não diferiram entre si.
\end{abstract}

Termos para indexação: goiabeira-serrana; desenvolvimento vegetativo; grau de produção.

\section{Growth and phenological attributes of pineapple-guava cultivars in São Joaquim, SC}

Abstract - The pineapple-guava plant belongs to Myrtaceae family and it is a species of spontaneous occurrence in South of Brazil, Uruguay and Argentina. Despite its adaptability and productive potential, the pineapple-guava is still not being planted in large scale, as it happens in others countries were the species was introduced and has been widely cultivated. Four commercial cultivars were created by Epagri and the Universidade Federal de Santa Catarina aiming to promote the pineappleguava farming in Brazil. The objective of this study is to evaluate the vegetative, phenological and productive development of the cultivars during three seasons. No difference in the vegetative development were observed among the cultivars, related to the trunk diameter and plant height. The production analysis indicated that, at least in two of the harvests evaluated, the cultivars Alcantara and Helena were superior that cvs. Nonante and Mattos.

Index terms: pineapple-guava; production degree; vegetative development.

A goiabeira-serrana (Acca sellowiana (Berg.) Burret.), também conhecida como 'feijoa', é uma espécie frutífera nativa do sul do Brasil e nordeste do Uruguai, pertencente à família Myrtaceae. É muito apreciada pelo consumidor devido à qualidade dos frutos que produz, os quais podem ser consumidos in natura ou serem processados na forma de geleias, sucos, doces, bebidas e sorvetes (DUCROQUET et al., 2008; AMARANTE \& SANTOS, 2013). Ademais, suas propriedades organolépticas e nutracêuticas (WESTON, 2010) destacam a espécie como alternativa de cultivo em algumas regiões no sul do Brasil.

Apesar de ser nativa do planalto meridional brasileiro, ainda é pouco cultivada comercialmente na região. 0 cultivo comercial é realizado em países como Nova Zelândia e Colômbia, entre outros, principalmente com material genético oriundo do Uruguai (AMARANTE \& SANTOS, 2013).

No estado de Santa Catarina, devido ao trabalho de pesquisa iniciado ainda na década de 1980 pela Epagri, e posteriormente em parceria com a Universidade Federal de Santa Catarina, quatro cultivares foram lançados comercialmente, sendo eles Mattos, Alcântara, Helena e Nonante. As principais características dos cultivares estão relacionadas a padrão de formato, sabor, períodos de maturação e regularidade de produção (DUCROQUET et al., 2007; 2008). O cultivar Mattos é oriunda da seleção direta de uma planta silvestre encontrada num remanescente de Floresta Ombrófila Mista nas imediações da cidade de São Joaquim, e selecionada pela boa aparência e tamanho do fruto. Os demais cultivares são oriundas da seleção de seedlings advindos de frutos ou de cruzamentos entre diferentes materiais genéticos (DUCROQUET et al., 2008; CIOTTA et al., 2018).

A partir do lançamento de tais cultivares comerciais, além da manutenção de unidades demonstrativas para difusão do material obtido, estão sendo conduzidos projetos de médio e longo prazos, especialmente na Estação Experimental da Epagri em São Joaquim, no sentido de avaliar as mesmas sob diferentes condições de cultivo.

Conhecer o desenvolvimento, fases

Recebido em 20/2/2019. Aceito para publicação em 28/5/2019.

${ }^{1}$ Engenheira-agrônoma, Dra., Epagri/Estação Experimental de Lages, 88502-970 Lages, SC, fone (49) 3289-6419, e-mail: marlise@epagri.sc.gov.br.

2 Engenheira-agrônoma, Dra., UFSC, Campus Curitibanos, Rodovia Ulysses Gaboardi, 3000, 89520-000 Curitibanos, SC, fone: (49) 2122-0326, e-mail: karine. santos@ufsc.br.

${ }^{3}$ Engenheiro-agrônomo, Dr., Bolsista PNPD/Capes, Universidade Federal de Pelotas, Faculdade de Agronomia Eliseu Maciel, C.P. 354, 96010-900 Pelotas, RS, e-mail: mateus.pasa@gmail.com. 
fenológicas e a produção das plantas nas condições de cultivo a campo, ao longo dos anos, é importante ferramenta para auxiliar na recomendação técnica de cultivo. A partir de tais informações é possível definir práticas de manejo mais adequadas, tais como raleio, colheita, uso de produtos para o controle fitossanitário, entre outras. Diante disso, este estudo foi conduzido com o objetivo de avaliar parâmetros de crescimento, atributos fenológicos e de produção dos quatro cultivares comerciais lançados pela Epagri/UFSC, nas condições de cultivo a campo em São Joaquim (SC).

O experimento foi conduzido em pomar instalado na área da Epagri, Estação Experimental de São Joaquim, com os cvs. Mattos, Alcântara, Helena e Nonante. O pomar foi implantado em 2006 em uma área de $330 \mathrm{~m}^{2}$. Inicialmente, em abril de 2006, amostras de solo da área do experimento foram coletadas para análise. Conforme os resultados, foi realizada a correção da acidez com $400 \mathrm{~g} \mathrm{~m}^{-2}$ de calcário dolomítico e adubação fosfatada com $10 \mathrm{~g} \mathrm{~m}^{-2}$ de superfosfato triplo (SFT) e $10 \mathrm{~g} \mathrm{~m}^{-2}$ de Cloreto de potássio $(\mathrm{KCl})$. No inverno do mesmo ano, foram abertas as covas de plantio e ao longo de cada linha foram plantadas as mudas de cada cultivar, com espaçamento de 5,0x4,0m. O delineamento foi o inteiramente casualizado com 5 repetições. As avaliações foram realizadas nas safras 2012/13, 2013/14 e 2014/15 em todas as plantas úteis. No período do inverno, foram avaliados o diâmetro de tronco, a aproximadamente $30 \mathrm{~cm}$ do solo; a altura de planta, com régua; e o diâmetro da copa, com fita métrica, na parte mediana da copa. Para o acompanhamento da fenologia foi determinada data de início da brotação, data em que $10 \%$ das flores estavam abertas, e data final de floração (mais de $90 \%$ das flores caídas). Também foi avaliado o grau de flor, através de uma escala de Nota de 1 a 5 , sendo 1 menor grau e 5 o grau máximo de flor. Após o raleio dos frutos, a mesma escala crescente de 1 a 5 foi utilizada para determinar o grau de produção de frutos. Anualmente está sen- do realizada a poda durante o período de inverno, eliminando-se os ramos em excesso, geralmente de 1 a 3 por planta. O controle fitossanitário realizado preferencialmente com calda bordalesa e produtos à base de cobre, conforme a necessidade e de acordo com as recomendações técnicas de Santos et al. (2012). Os resultados de diâmetro de tronco e copa, bem como altura da planta, foram comparados entre os cultivares pelo teste de Tukey a $5 \%$ de probabilidade.

O diâmetro de tronco não diferiu entre os cultivares (Tabela 1 ). Segundo
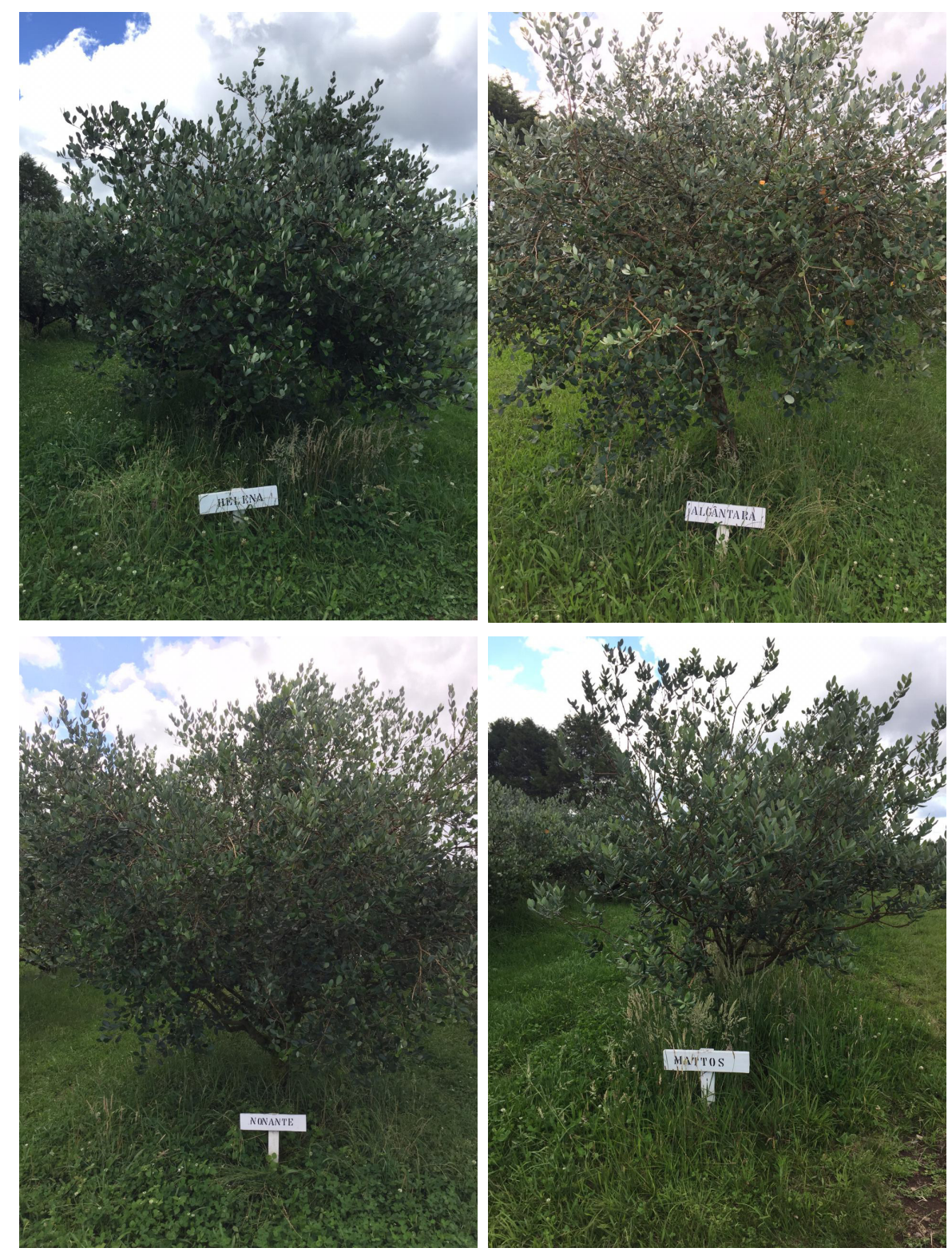

Figura 1. Cultivares de goiabeira-serrana (Acca sellowiana (Berg.) Burret.) A) Helena, B) Alcântara, C) Nonante e D) Mattos. Foto: Marlise N. Ciotta

Figure 1. Pineapple-guava (Acca sellowiana (Berg.) Burret.) cultivars A) Helena, B) Alcântara, C) Nonante and D) Mattos. Photo: Marlise N. Ciotta 
Tabela 1. Parâmetros de crescimento das plantas e atributos fenológicos dos cultivares de goiabeira-serrana (Acca sellowiana (Berg.) Burret.) na Estação Experimental da Epagri de São Joaquim - safras 2012/13, 2013/14 e 2014/15

Table 1. Plant growth parameters and phenological attributes of goiabeira-serrana (Acca sellowiana (Berg.) Burret.) cultivars at the Epagri Research Station of São Joaquim 2012/13, 2013/14 and 2014/15 seasons

\begin{tabular}{|c|c|c|c|c|}
\hline \multirow[t]{2}{*}{ Parâmetros } & \multicolumn{4}{|c|}{ Cultivar } \\
\hline & Alcântara & Nonante & Helena & Mattos \\
\hline & \multicolumn{4}{|c|}{--------------------------2012/13-------------------------- } \\
\hline Diâmetro de tronco $(\mathrm{cm})$ & $71,6^{\mathrm{ns}}$ & 71,5 & 57,0 & 50,1 \\
\hline Altura de planta $(\mathrm{cm})$ & $219,4^{\text {ns }}$ & 215,3 & 190,4 & 237,1 \\
\hline Diâmetro de copa (cm) & $192,0^{\text {ns }}$ & 184,8 & 169,2 & 136,1 \\
\hline Início de brotação & $03 / 10$ & 03/10 & $03 / 10$ & 03/10 \\
\hline Infloresc $10 \%$ aberta & 08/11 & $10 / 11$ & 08/11 & 08/11 \\
\hline Fim floração (90\% caída) & $13 / 12$ & $12 / 12$ & $15 / 12$ & $05 / 12$ \\
\hline Grau de flor & 5 & 3 e 4 & 4 e 5 & 3 e 4 \\
\hline \multirow[t]{2}{*}{ Grau de produção } & 3 & 2 & 4 & 1 \\
\hline & \multicolumn{4}{|c|}{----------------------------2013/14-------------------------' } \\
\hline Diâmetro de tronco $(\mathrm{cm})$ & $88,0^{\text {ns }}$ & 87,5 & 78,2 & 67,5 \\
\hline Altura de planta $(\mathrm{cm})$ & $261,8^{\text {ns }}$ & 253,5 & 201,2 & 227,4 \\
\hline Diâmetro de copa (cm) & $247,4^{\text {ns }}$ & 220,8 & 202,0 & 172,7 \\
\hline Início de brotação & $08 / 10$ & $06 / 10$ & $08 / 10$ & 03/10 \\
\hline Infloresc $10 \%$ aberta & $10 / 11$ & $20 / 11$ & $01 / 11$ & $01 / 11$ \\
\hline Fim floração (90\% caída) & $07 / 12$ & $10 / 12$ & $03 / 12$ & $28 / 11$ \\
\hline Grau de flor & 4 & 4 & 4 & 3 \\
\hline \multirow[t]{2}{*}{ Grau de produção } & 3 & 2 & 3 & 1 \\
\hline & \multicolumn{4}{|c|}{-----------------------------2014/15------------------------' } \\
\hline Diâmetro de tronco $(\mathrm{cm})$ & $89,0^{\text {ns }}$ & 103,0 & 79,2 & 82,2 \\
\hline Altura de planta $(\mathrm{cm})$ & $283,2^{\text {ns }}$ & 262,3 & 224,4 & 262,9 \\
\hline Diâmetro de copa (cm) & $273,2^{\text {ns }}$ & 247,8 & 236,0 & 214,8 \\
\hline Início de brotação & $01 / 10$ & $04 / 10$ & $27 / 09$ & $03 / 10$ \\
\hline Infloresc $10 \%$ aberta & $11 / 11$ & $06 / 11$ & $28 / 10$ & $08 / 11$ \\
\hline Fim floração (90\% caída) & $30 / 11$ & $04 / 12$ & $01 / 12$ & $30 / 11$ \\
\hline Grau de flor & 4 e 5 & 4 e 5 & 4 e 5 & 2 e 3 \\
\hline Grau de produção & 5 & 4 & 5 & 3 \\
\hline
\end{tabular}

${ }^{\text {ns }}$ não significativo a $5 \%$ de probabilidade
A altura de planta e o diâmetro de copa não diferem entre os cultivares, confirmando as características de porte descritas para os cultivares (DUCROQUET et al., 2007, 2008). Plantas com altura próxima à $2,5 \mathrm{~m}$ são desejáveis por questão de manejo, especialmente colheita, entre outros tratos culturais.

$O$ grau de florescimento foi igual nos cvs. Alcântara, Helena e Nonante, nas safras 2013/14 e 2014/15, e superior no Mattos na primeira safra. Porém, isso não se refletiu no grau de produção dos cultivares, sendo Alcântara e Helena superiores ao Nonante. $\mathrm{O} \mathrm{cv}$. Mattos, nos três anos, apresentou o menor grau de flor, o que se refletiu em menor grau de produção. Resultados apresentados por Ducroquet et al. (2007 e 2008), quando no lançamento dos cultivares mostram que o índice de produtividade foi maior nos cvs. Helena e Alcântara.

Independente do cultivar, o início da brotação ocorre normalmente a partir do mês de outubro, exceção aconteceu para o cv. Nonante na safra 2014/15. No entanto, uma importante diferença entre os cultivares é a duração do período de florescimento. Nos três anos, o cv. Helena apresentou o maior período de florescimento, acima de 32 dias, seguido pelo cv. Alcântara, pelo menos nos dois primeiros anos de avaliação. Essa característica é importante para potencializar a polinização e a frutificação. Além disso, permite conhecer o período de concentração da produção, reduzindo os riscos a produção das culturas (ANTUNES et al., 2008). Em 23 cultivares de pessegueiros, Thomaz et al. (2010) observaram que a floração mais concentrada no tempo proporciona colheita mais uniforme. $O$ grau de produção de todos os cultivares foi sempre maior que 3 (considerado médio), demonstrando o potencial produtivo dos mesmos. Para os cvs. de goiabeiraserrana, o cv. Alcântara é o primeiro a ser colhido (início de março), seguido por Mattos, Helena e Nonante (CIOTTA et al., 2018). Cultivares da Nova Zelândia, onde a fruta apresenta produção e comércio já consolidados, são variáveis 
em relação à precocidade de produção e características do fruto. Por exemplo, o 'Unique' é bastante precoce e com tamanho de fruto pequeno a médio; já o 'Apollo' é de média precocidade e dá frutos maiores (THORP \& BIELESKI, 2002). No entanto, tanto número quanto o peso de frutos de tais cvs. são menores comparativamente aos genótipos brasileiros (THORP \& BIELESKI, 2002), possivelmente por características de seleção e melhoramento diferenciadas entre os países. Além disso, como é uma fruta nativa do Brasil, a goiabeiraserrana apresenta maior diversidade de acessos para seleção.

De um modo geral os resultados mostram que há diferenças nos parâmetros de crescimento de cada cultivar, o que se reflete também no grau de produção dos cultivares avaliados. E, neste sentido, os cvs. Alcântara e Helena apresentaram maior grau de produção.

\section{Agradecimento}

Ao colega Humberto Ribeiro Nunes, técnico agrícola da Estação Experimental da Epagri de São Joaquim, pelo apoio e o auxílio na condução das atividades de campo.

\section{Referências}

AMARANTE, C.V.T; SANTOS, K.L. Goiabeiraserrana (Acca sellowiana). Revista Brasileira de Fruticultura, Jaboticabal, SP, v.33, n. 1 p.001-334, 2013.

ANTUNES, L.E.C.; GONÇALVES, E.D.; RISTOW, N.C. et al. Fenologia, produção e qualidade de frutos de mirtilo. Pesquisa Agropecuária Brasileira, Brasília, DF, v.43, n.8, p.10111015, 2008.

CIOTTA, M.N.; ARIOLI, C.J.; PINTO, F.A.M.F.; SANTOS, K. dos; ARAUJO, L.; PASA, M. da S. (Orgs.). A cultura da goiabeira-serrana. Florianópolis: Epagri, 2018. 216p.

DUCROQUET, J.P.H.J.; SANTOS, K.L., ANDRADE, E.D., BONETI, J.I.S., BONIN, V.. As primeiras cultivares brasileiras de goiabeira serrana: SCS411 Alcântara e SCS412 Helena. Agropecuária Catarinense, Florianópolis, v. 20, p.77-80, 2007

DUCROQUET, J. P. H. J., NUNES, E., GUERRA, M.P., NODARI, R.O.. Novas cultivares brasileiras de goiabeira-serrana SCS414 Mattos e SCS415 Nonante. Agropecuária Catarinense, Florianópolis, v. 21, n. 2, p.77-80, 2008
FISCHER, G. Ecofisiología, crecimiento y desarrollo de la feijoa pp. 9-26. En: Fischer, G.,

D. Miranda, G. Cayón y M. Mazorra (eds.). Cultivo, poscosecha y exportación de la Feijoa (Acca sellowiana Berg). Produmedios, Bogotá, 2003, 152 p.

SANTOS, K. L. dos (Org.) Orientações para o cultivo da goiabeira serrana (Acca sellowiana). Florianópolis: Epagri, 2 ed., 2012 44p. (Boletim Técnico, 153)

TOMAZ, Z.F.P.; LIMA, C.S.M.; GONÇALVES, M.A.; RUFATO, L.; RUFATO, A.D.R. Crescimento vegetativo, floração e frutificação efetiva do pessegueiro 'Jubileu' submetido a diferentes comprimentos de interenxertos. Pesquisa Agropecuária Brasileira, Brasília, DF, v. 45, n. 9, p. 973-979, 2010.

THORP, T.G.; BIELESKI, R. Feijoas: origins, cultivation and uses. Auckland: David Bateman, 2002. 87p

WESTON, R.J. Bioactive products from fruit of the feijoa (Feijoa sellowiana, Myrtaceae): A review. Food Chemistry, v.121, p. 923-926, 2010 .

\section{Siges a Epagjij nas redes socialis}
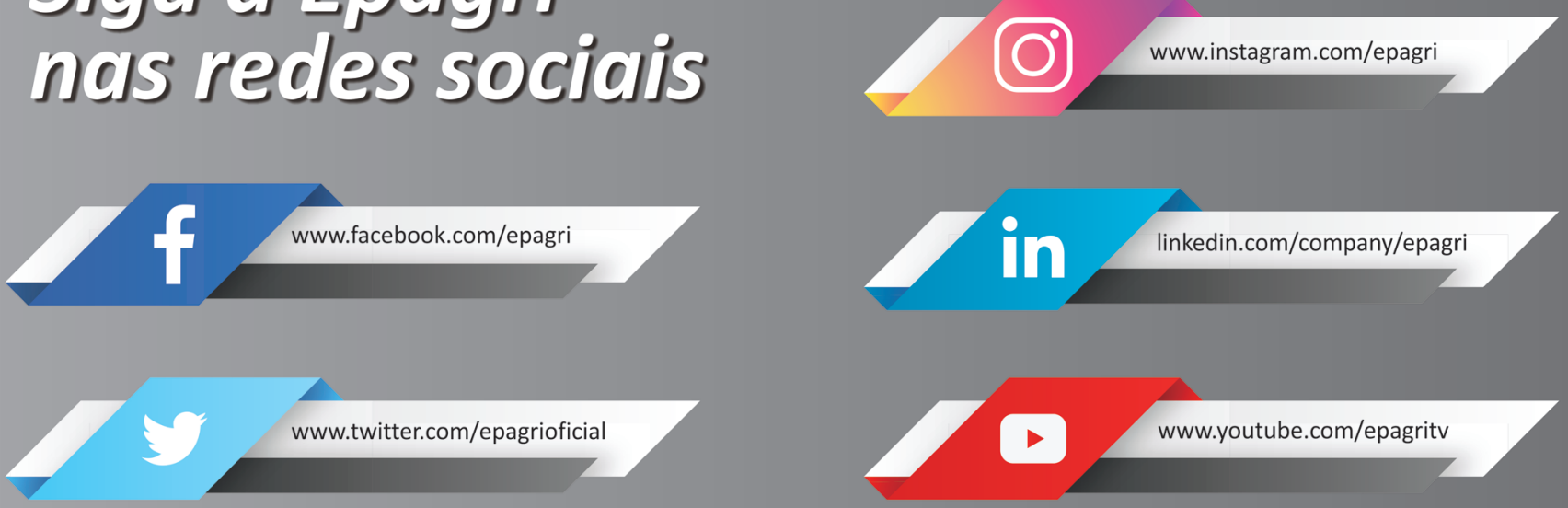